\title{
Characteristics of the Literature of Literary Scholarship
}

\section{Madeleine Stern}

The aim of the study was to determine how researchers use the literature that constitutes literary scholarship. For this purpose three creative writers and three literary movements were selected for analysis. The 1976-80 volumes of the Arts and Humanities Citation Index provided access to the articles written on the subjects chosen. The references cited by the authors of the articles, along with the form analysis of the articles themselves, constituted the substance on which the results of the study were based.

The results support the contention that humanistic scholarship and the methods by which its characteristics are studied and analyzed are distinct and unique and require different methodology than that used for the analysis of information transfer in the sciences and social sciences.

he purpose of this study is to try to determine how researchers use the literature that constitutes literary scholarship. The assumption is that this type of scholarship is characterized by unique attributes and that its methodologies and research tools differ from those in other disciplines in the humanities and most certainly in the sciences and social sciences.

The major thrust of literary scholarship is a critical concern for past and present creative writing. This critical concern may center around an author and his works, around the concept of critical theory itself, or around the formulation of literary theories based on historical or cultural approaches to criticism.

The present study aims to focus on the two former aspects of critical concerns in literary scholarship, namely on research on creative writers and their work and on research on the theory and approaches to literary criticism.

\section{METHODOLOGY}

To examine how researchers in literary criticism use the literature on creative writers, and on the theory and approaches to literary criticism, three creative writers and three literary movements were selected for analysis. The authors chosen were John Milton, Henry James, and W. $\mathrm{H}$. Auden; the literary movements were Symbolism, Existentialism, and Structuralism. The $1976-80$ volumes of the Arts and Humanities Citation Index (A\&HCI) provided access to articles written on the subjects. The references cited by the authors of the articles, along with the form analysis of the articles themselves, constituted the substance on which the results of the study were based.

The Permuterm Subject Index was the starting point for the study. This index lists every significant English word in the titles of source articles indexed by $A \mathcal{E H C I}$. 'Beneath these 'primary terms' are listed alphabetically the 'co-terms' which appeared with it in titles. Opposite each 'co-

Madeleine Stern is head, Collection Development, Lockwood Memorial Library, State University of New York at Buffalo. 
term' is the name of the author of the [source article] whose title includes the primary and the 'co-term'." While this method identified the creative writers and literary movements written about during the latter part of the 1970 s, it did not necessarily identify all scholarly articles about these authors and literary movements indexed in the $A \mathcal{E} H C I$. Nevertheless, it was felt that the appearance of the name of the author and of the movement in the title established in all instances a high degree of subject relevance, i.e., if an author's name appeared in the title it was more likely that the article was about the author than if his name did not appear in the title.

Once the authors of the articles were thus identified, the "Source Index" section of $A \mathcal{E} H C I$ was consulted as a second step to the compilation of data for the analysis. The "Source Index" is an author index arranged alphabetically, and each entry includes the name of all authors, full title of the article, the title of the journal, volume, issue, pages, and year of publication. Beneath this bibliographic description appears, alphabetically by author, the list of references cited by the author of the source article. This listing includes the cited author's name, the cited work or the title of the journal if the cited work is an article, the year of publication, and page number. The $A \mathcal{E H C I}$ differs from the $S C I$ and the SSCI in that it goes beyond the practice of indexing only references cited in the bibliography or the footnotes of the source article. It also includes as cited items "works of art (novels, paintings, musical compositions, etc.) which are the subjects of the articles, even though they were not formally cited.",2 AEHCI calls these "implicit" citations, and they are indicated by an arrow next to the cited title.

From the "Source Index" entries, it was possible to determine whether the source article was a general article, a book review, or a number of other types of publications. The list of the cited items were classified according to form into books, journals, and "other," which included manuscripts, various communications, encyclopedias, dictionaries, theses, and illustrations. The cited items were divided according to content into primary sources and secondary sources. In the study on creative writers, the primary sources were further divided into the works of the writer and other primary source materials. The publication dates of the cited items provided the data for the study on date distribution.

Two problems arose when this methodology was applied. Both of them can be attributed to the unique character of the literature that deals with the works of creative writers and the method $A \mathcal{E H C I}$ employs to deal with them. By instituting the practice of "implicit" citations, $A \mathcal{E H C I}$ recognized the fact that creative works are the products of one person's artistic and imaginative thought processes, and the scholarship that illuminates them and provides access to them cites and refers to them differently than when scientists and social scientists cite material relevant to the articles they write. A creative work may be quoted extensively within the text of the article, it may be mentioned in comparison with some other works, or referred to frequently within the text in connection with the thesis the author of the article wishes to expound. These references may appear as formal citations in footnotes or bibliographies in the same format. These may follow the same conventions used for citations in other academic disciplines, or the author of the article may state in a footnote that all references to the cited works are to a particular edition of the discussed writer's complete or selected works. Alternatively, the work referred to or quoted in the text of the article may not appear at all in formal footnotes or bibliographies. For these instances, $A \mathcal{E H C I}$ established the practice of indexing "implicit" citations. As a consequence of this indexing practice, the mechanical aspect of indexing only what is formally cited is now expanded into a judgmental function, where the indexer has to scan the text and make a decision as to what to include as an "implicit" citation. Thus, the subjective and interpretive element that characterizes literary scholarship, and differentiates it from scholarship in other disciplines, becomes incorporated into humanistic citation indexing practices as well. In checking the source 
articles against the entries in the "Source Index," there were frequent questions as to why some references were indexed and some omitted. In spite of these ambiguities, both the formal and "implicit" citations were counted and tabulated as they appeared in the "Source Index" beneath the bibliographic description of the source article.

A related problem arose from the practice of literary researchers citing collected works. $A \mathcal{E H C I}$ indexes these, sometimes under the name of the creative writer, and sometimes under the name of the editor. In some circumstances the individual works are also indexing terms, but not in all instances. In the study the citations of collected editions were always counted as primary sources under the creative writer's name, unless it was determined from the article that the reference was to the editor's comments or opinions. In these cases the citation was counted as a secondary source. The primary source count in the study on creative writers included the citations to the complete works as well as to the individual works, cited formally as well as implicitly.

For each of the six subjects, three full or partial years of the $A \mathcal{E} H C I$ (between the years of 1976 and 1980) were utilized as a database. The bibliometric count displayed in tables 1 and 2 indicates the number of source items and the number of references counted, and the percentages of the totals for each subject. While the actual numbers of the counted items varied in size, the percentages showed general internal consistency - a variance of not more than 10 percent-with the exception of the subgroup of secondary source references in the James, Auden, and Existentialism counts.

For the age distribution count (see tables 3 and 4), the publication dates were divided into ten-year segments to 1920 , one twenty-year span from 1920 to 1900 , and one segment for all dates prior to 1900 . A relatively large proportion of the cited items in the $A \mathcal{E} H C I$ lacked publication dates. This was partly due to omissions by the authors of the source articles, and partly due to omission of the cited date in the source article by the indexers of the
$A \mathcal{E H C I}$. Wherever the publication dates were ascertainable, they were added to the count and tabulated. Citations with unascertainable dates were not included in the age distribution analysis.

\section{THE WRITER AND HIS WORKS}

While ancillary topics, such as sources of a writer's work, his life, influence on other writers, comparisons with other authors' works, and relationships between his life and his writing have always been an integral part of literary research, the fundamental and predominant subject of investigation has remained the text itself. The study of the creative process, manifested by those who commit their thoughts and imagination to paper, is a historical, cumulative continuum. Writings of the most contemporary authors become part of literary history once they are committed to the printed and published page. As students and scholars dissect and scrutinize these writings, a subfield of primary texts emerges and continues to expand. This subfield, a cross between primary and secondary source materials, comprises the large variety of publications beyond the first edition of an author's creative work. This critical apparatus surrounding the creative process in literature adds another dimension to it, is the most distinctive feature of literary scholarship, and is shared to varying degrees by other humanistic disciplines.

In selecting Milton, James, and Auden as subjects of these investigations, I intended to examine the influence of the time element on the corpus of research into the writings of authors separated from one another by centuries. Does the accumulation of works on Milton, as utilized by current researchers, differ in form and content from current research on the creative output of Auden? Does current Milton scholarship differ from current Auden scholarship? How does the accumulation of evaluative, revisionist, or other critical writings of the past influence the practitioners of present-day literary research? How important are primary sources? Is there any significant difference in the time span of these materials used by scholars? 
TABLE 1

CREATIVE WRITERS: SOURCE ARTICLE AND REFERENCE ANALYSIS

\begin{tabular}{|c|c|c|c|c|c|c|c|c|c|c|c|}
\hline & no. & $\begin{array}{l}\text { Source Items } \\
\text { Book Rev. } \\
\%\end{array}$ & $\begin{array}{c}\text { Articles } \\
\%\end{array}$ & no. & $\begin{array}{c}\text { Refere } \\
\text { Books } \\
\%\end{array}$ & $\begin{array}{c}\text { (Form) to: } \\
\text { Journals } \\
\%\end{array}$ & $\begin{array}{c}\text { Other } \\
\%\end{array}$ & no. & $\underset{\%}{\text { Authors* }}{ }^{\mathrm{F}}$ & $\begin{array}{c}\text { References (Content) to: } \\
\text { Other Primary } \\
\%\end{array}$ & $\begin{array}{c}\text { Secondary } \\
\%\end{array}$ \\
\hline $\begin{array}{l}\text { Milton } \\
1976 \\
1979 \text { (Jan-Apr) } \\
\text { 1980(Jan-Aug) } \\
\text { Totals }\end{array}$ & $\begin{array}{r}70 \\
32 \\
72 \\
174\end{array}$ & $\begin{array}{l}57 \\
56.3 \\
55.6 \\
56.3 \%\end{array}$ & $\begin{array}{l}43 \\
43.7 \\
44.4 \\
43.7 \%\end{array}$ & $\begin{array}{r}491 \\
370 \\
739 \\
1600\end{array}$ & $\begin{array}{l}86.2 \\
87 \\
83 \\
89.9 \%\end{array}$ & $\begin{array}{l}11.8 \\
10.3 \\
13.5 \\
12.2 \%\end{array}$ & $\begin{array}{l}2 \\
2.7 \\
3.4 \\
2.8 \%\end{array}$ & $\begin{array}{r}491 \\
370 \\
739 \\
1600\end{array}$ & $\begin{array}{l}18.5 \\
27.8 \\
14.9 \\
19 \%\end{array}$ & $\begin{array}{l}26.3 \\
18.4 \\
26 \\
24.3 \%\end{array}$ & $\begin{array}{l}55.2 \\
53.8 \\
59.1 \\
56.7 \%\end{array}$ \\
\hline $\begin{array}{l}\text { Auden } \\
1976 \\
1978 \\
1979 \text { (Jan-Aug) } \\
\text { Totals }\end{array}$ & $\begin{array}{l}15 \\
21 \\
11 \\
47\end{array}$ & $\begin{array}{l}33.3 \\
33.3 \\
36.4 \\
34 \%\end{array}$ & $\begin{array}{l}66.7 \\
66.7 \\
63.6 \\
66 \%\end{array}$ & $\begin{array}{r}99 \\
166 \\
150 \\
415\end{array}$ & $\begin{array}{l}76.8 \\
75.3 \\
88 \\
80.2 \%\end{array}$ & $\begin{array}{l}23.2 \\
21.6 \\
10 \\
17.8\end{array}$ & $\begin{array}{l}2 \\
2 \\
2 \\
2 \%\end{array}$ & $\begin{array}{r}99 \\
166 \\
150 \\
415\end{array}$ & $\begin{array}{l}51.5 \\
38.5 \\
39.3 \\
41.9 \%\end{array}$ & $\begin{array}{l}12.1 \\
10.1 \\
16 \\
12.8 \%\end{array}$ & $\begin{array}{l}36.4 \\
51.2 \\
44.6 \\
45.3 \%\end{array}$ \\
\hline $\begin{array}{l}\text { H. James } \\
1980 \text { (Jan-My) } \\
1977 \\
1979 \text { (Jan-Apr) } \\
\text { Totals }\end{array}$ & $\begin{array}{r}56 \\
25 \\
25 \\
106\end{array}$ & $\begin{array}{l}64.2 \\
44 \\
60 \\
58.5 \%\end{array}$ & $\begin{array}{l}35.8 \\
56 \\
40 \\
41.5 \%\end{array}$ & $\begin{array}{l}413 \\
221 \\
227 \\
861\end{array}$ & $\begin{array}{l}81.6 \\
84.6 \\
84.1 \\
83 \%\end{array}$ & $\begin{array}{l}16.2 \\
15.4 \\
13.7 \\
15.3 \%\end{array}$ & $\begin{array}{l}2.1 \\
2 . \overline{2} \\
1.6 \%\end{array}$ & $\begin{array}{l}413 \\
221 \\
227 \\
861\end{array}$ & $\begin{array}{l}24.9 \\
24.4 \\
42.3 \\
29.4 \%\end{array}$ & $\begin{array}{c}18.4 \\
13.1 \\
9.7 \\
14.7 \%\end{array}$ & $\begin{array}{l}56.5 \\
62.4 \\
48 \\
55.9 \%\end{array}$ \\
\hline
\end{tabular}

TABLE 2

LITERARY THEORY: SOURCE ARTICLE AND REFERENCE ANALYSIS

\begin{tabular}{|c|c|c|c|c|c|c|c|c|c|c|}
\hline & no. & $\begin{array}{l}\text { Source Items } \\
\text { Book Rev. } \\
\%\end{array}$ & $\begin{array}{c}\text { Articles } \\
\%\end{array}$ & no. & $\begin{array}{c}\text { Refer } \\
\text { Books } \\
\%\end{array}$ & $\begin{array}{l}\text { Form) to: } \\
\text { Journals } \\
\%\end{array}$ & $\begin{array}{c}\text { Other } \\
\%\end{array}$ & no. & $\begin{array}{l}\text { References (Content) to: } \\
\text { Primary } \\
\%\end{array}$ & $\underset{\%}{\text { Secondary }}$ \\
\hline \multicolumn{11}{|l|}{ Symbolism } \\
\hline 1976 & 58 & 32.8 & 67.2 & 818 & 73.6 & 13.8 & 12.6 & 818 & 30.3 & 69.7 \\
\hline 1978 & 38 & 39.4 & 60.6 & 595 & 73.6 & 17.3 & 9.1 & 595 & 33 & 67 \\
\hline 1979 (Jan-Apr) & 42 & 33.3 & 66.6 & 570 & 78.8 & 15 & 6.1 & 570 & & 72 \\
\hline Totals & 138 & $35.1 \%$ & $64.8 \%$ & 1983 & $75.1 \%$ & $15.2 \%$ & $9.7 \%$ & 1983 & $30.5 \%$ & $69.5 \%$ \\
\hline \multicolumn{11}{|l|}{ Structuralism } \\
\hline 1976 & 70 & 60 & 40 & 575 & 80.6 & 16.9 & 2.6 & 575 & 9.7 & 90.3 \\
\hline 1978 & 48 & 66.6 & 33.4 & 698 & 77 & 22 & 1 & 698 & 7.9 & 92.1 \\
\hline 1979 (Jan-Apr) & 18 & 61 & 39 & 270 & 73.3 & 25.1 & 1.5 & 270 & 7 & 93 \\
\hline Totals & 136 & 62.5 & 37.5 & 1543 & 77 & 21.3 & 1.7 & 1543 & 8.4 & 91.6 \\
\hline \multicolumn{11}{|l|}{ Existentialism } \\
\hline 1976 & 36 & 47.2 & 52.7 & 250 & 84 & 12.4 & 3.6 & 250 & 20.8 & 79.2 \\
\hline 1978 & 26 & 34.6 & 65.4 & 275 & 84.4 & 15.6 & - & 275 & 29.4 & 70.6 \\
\hline 1979 (Jan-Apr) & 16 & 37.6 & 62.5 & 93 & 73 & 14 & 6 & 43 & 43 & 57 \\
\hline Totals & 78 & $41 \%$ & $59 \%$ & 618 & $83.3 \%$ & $14.3 \%$ & $2.4 \%$ & 618 & $28 \%$ & $72 \%$ \\
\hline
\end{tabular}


TABLE 3

CREATIVE WRITERS: AGE DISTRIBUTION OF ALL REFERENCES $\%$ OF REFERENCES

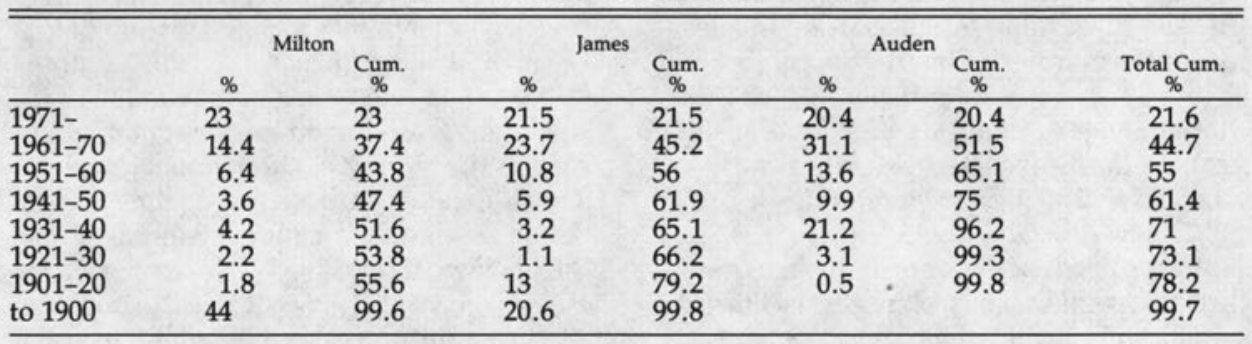

TABLE 4

LITERARY THEORY: AGE DISTRIBUTION OF ALL REFERENCES $\%$ OF REFERENCES

\begin{tabular}{|c|c|c|c|c|c|c|c|}
\hline & \multicolumn{2}{|c|}{ Symbolism } & \multicolumn{2}{|c|}{ Existentialism } & \multicolumn{2}{|c|}{ Structuralism } & \multirow[b]{2}{*}{$\begin{array}{c}\text { Total Cum. } \\
\%\end{array}$} \\
\hline & $\%$ & Cum. & $\%$ & Cum. & $\%$ & $\underset{\%}{\text { Cum. }}$ & \\
\hline 1971- & 21 & 21 & 25.8 & 25.8 & 44 & 44 & 30.3 \\
\hline $1961-70$ & 19.8 & 40.8 & 31 & 56.8 & 34 & 78 & 58.5 \\
\hline $1951-60$ & 9.9 & 50.7 & 17.5 & 74.3 & 8.7 & 86.7 & 70.4 \\
\hline $1941-50$ & 4.2 & 54.9 & 7.3 & 81.6 & 2.4 & 89.1 & 75.2 \\
\hline $1931-40$ & 2.9 & 57.8 & 6.3 & 87.9 & 2.9 & 92 & 79.2 \\
\hline $1921-30$ & 2.9 & 60.7 & 2.3 & 90.2 & 2.3 & 94.3 & 81.7 \\
\hline $1901-20$ & 8.4 & 69.1 & 2.8 & 93 & 2 & 96.3 & 86.1 \\
\hline to 1900 & 30.9 & 100 & 6.5 & 99.5 & 3.8 & 100.1 & 99.7 \\
\hline
\end{tabular}

Source articles that dealt with the three authors were of two types: book reviews and articles. From the start of the investigation, the large number of book reviews was quite apparent, a clear indication in itself of the book-oriented nature of literary scholarship. More than one-half of the source articles about Milton and James were book reviews, 56.3 percent and 58.5 percent, respectively, and 34 percent in the case of Auden. These figures don't indicate that each review article reviewed a different book. The same book would be reviewed in several articles and there may be a correlation between the importance of the book and its author and the number of times it was reviewed. Nevertheless, the preponderance of book reviews as a tool of literary scholarship seems to be one of the characteristics of the discipline; it also indicates the importance literary scholars attach to the monographic form for publishing research results. The markedly lower proportion of book reviews as source articles on Auden, a mid-twentieth century author, would suggest that contempora- neity is a factor in the size of monographic literature being currently written about writers or poets. Auden's work has not been around long enough to elicit monographic treatment from scholars to the same degree as that of the likes of Milton or James.

For the 327 source articles dealing with Milton, James, and Auden, the AEHCI listed a total of 2,876 references. (These do not necessarily correspond to the formal footnotes or bibliographic notes in the articles.) Of these, 82.7 percent were references to books, 15.1 percent to articles, 2.2 percent to other types of materials such as dissertations, encyclopedias, unpublished communications, and a few manuscripts. Jones, Chapman, and Woods in their study found that even though archival records are the historian's primary research sources, manuscript and other unpublished materials were cited surprisingly infrequently. In their study, 12.6 percent of all references were to unpublished material, and 87.4 percent pertained to published material. ${ }^{3}$ The insig- 
nificant number of manuscripts used by the authors of the.source articles may be accounted for by the fact that the research into the topic of an article is done in a less in-depth manner than if the published study were a full-length book. I suspect that analysis of citations in source monographs dealing with the same subject would yield a higher percentage of unpublished primary source citations.

The prominence of monographic literature as it pertains to contemporary literary scholarship in the area of creative writing is unmistakable. While previous studies on overall patterns of literature use in the humanities clearly indicate that the bulk of references are to monographs, literature dealing with the works of creative writers shows the highest percentage of monograph use. One must examine these figures with some caution, however, because the definition of book or monograph in the analysis of the forms of material cited might vary from study to study. Broadus, in his survey of citation studies, cites Vaughan, who found in music that 69.5 percent of the references were to "monographs" and Simonton, who in his study of fine-arts literature shows that 71.4 percent of the citations were to "books. ${ }^{\prime 4}$ Heinzkill, in his study of citations in English literary journals, found that 75 percent of all citations were to books. ${ }^{5}$

The source articles dealing with Milton had 84.9 percent of their references to books, 12.2 percent to articles, and 2.8 percent to other forms. Those on James had 83 percent of their references to books, 15.3 percent to articles, and 1.6 percent to other forms. In the case of Auden, 80 percent of the references were to books, 17.8 percent to articles, and 1.9 percent to others.

The time span that separates current scholarship from the subject studied seems to be a factor here. Knowledge and scholarship in literary studies is cumulative. Works of scholars of previous decades or centuries are not superseded or discarded. The same literary text may be the subject of investigation and of textual analysis over and over again. The apparatus criticus necessary for the preparation of definitive editions, manuscripts, let- ters, and other communication are all characteristic of humanistic research, and of literary research more specifically. As the citation analysis suggests, the book is the form through which this type of scholarly work is presented and because of its cumulative and encompassing nature, the further the subject of the scholarly investigation extends into the past, the heavier the investigator's reliance on the book form will be for study. While the major literary form cited by scholars is the book for all three authors, there is a heavier reliance on books in the case of Milton than in the case of the twentieth-century poet Auden.

Heavy reliance on primary source materials is one of the most distinctive characteristics of literary research in general, and for the writings of individual authors in particular. In the study of recent articles about Milton, James, and Auden, 47.4 percent of all the references were to primary materials; 43.3 percent of the references to Milton, 44.1 percent to James, and 54.7 percent to Auden were primary material. It would seem that the more contemporary the author, the greater is the use made of primary sources by scholars to investigate, study, and evaluate the author's work. The more contemporary the author, the fewer are the number of critical works available to researchers for their studies. By virtue of the paucity of previous research into their work, research on contemporary authors must depend more on the texts themselves. In the case of a literary figure of the nineteenth or seventeenth century, the work has already been studied, dissected, documented, and evaluated by previous generations of literary scholars. A closer analysis of the primary materials used for this study will further confirm this characteristic. Primary material, as cited in scholarly articles on literature, can be divided into works of the authors who are the subject of the source article, and other primary works that are the creative products of other authors. In the source articles on Milton, this division indicates that 19 percent of the references to primary materials were to Milton's works and 24.3 percent to the works of other authors; in James' case 29.4 
percent were to his work and 14.7 percent to the works of other authors; in the articles about Auden 41.9 percent of the references to primary materials were to the works of Auden and 12.8 percent to other authors. The 19 percent of references to Milton's works and the 41.9 percent to Auden's might possibly indicate a paucity of output by Milton as opposed to relatively greater prolificity by Auden. I don't believe that this is a matter of quantity. The single work Paradise Lost may be cited and quoted line by line, chapter by chapter more frequently than dozens of Auden's poems. The difference lies in the manner in which researchers utilize materials for their research. The more distant the creative writer's work, the larger is the body of secondary literature built around it, so that the researcher does not have to rely exclusively on the text itself in order to support his judgment or interpretation. In the case of references to primary sources other than the creative writer's works, the study shows a reverse of percentages. The lowest percentage, 12.8 percent, was for source articles dealing with Auden; the highest, 24.3 percent, dealt with Milton, with James-related articles showing 14.7 percent of the references to other primary sources. The same phenomenon may account for this practice as for the above, where the reliance on secondary material is heavier for the distant author than for the contemporary one. In one sense this type of primary source material takes on the function of secondary material, where the works of other creative writers are scrutinized and compared with the work or works of the author who is the subject of the source article.

Analysis of the publication dates presented difficulties and required adjustments because of citation indexing practices and occasional inconsistencies in the $A \mathcal{E H C I}$. The citation index contains an unreasonably large number of undated citations, mostly to primary sources. In these instances publication dates of the first edition of the works cited were added and counted. Citations with unascertainable dates were not counted in the age distribution analysis. A reference may also be a citation to a complete, part of a complete, edited, or revised edition, in which case the publication date is later than that of the first edition. Consequently, the analysis of the age distribution reflects a combination of contemporaneous and later publication of primary source materials. For instance, in the source articles on Milton, 44 percent of all references were to publications prior to 1900 because a large percentage of the citations ( 43.3 percent) were to Milton and to other primary source materials first published prior to 1900 . Yet some additional citations were also made to later, revised editions, which are reflected in the distribution for later time periods. In the Milton studies 37.4 percent of all the cited material was twenty years old or less, while these figures are 45.2 percent and 51.5 percent for the James and Auden studies, respectively. The longer the time span between the creative writer's contribution and the work about him, the further back the literary scholar reaches for material. There is an indication here to the validity of statements about humanistic scholarship being cumulative and least susceptible to obsolescence. At the same time, it is interesting to note that current publications that consist mostly of secondary sources, plus new editions of primary sources, seem to be important and at an equal level for all three. Twenty-three percent of the references on Milton were ten years old or less at the time the source article was written. These percentages for James and Auden were 21.5 and 20.4, respectively. The importance of contemporary material consisting largely of the writings of the creative writer is reflected also in the median citation age of the references used in the source articles. Fifty percent of the references in the articles on Milton were published within fifty years of the date of the source article. Fifty percent of the references on James were published within approximately twenty-five years, and 50 percent of the references on Auden were published within twenty years.

The least productive years on the pretwentieth century authors seem to be the $1920 \mathrm{~s}$, with 2.2 percent and 1.1 percent of the references to Milton and James, respectively. Citations in the articles dealing 
with Auden drop sharply after the high in the thirties (a decade of high productivity for Auden) with no citations dating from the pre-1900 period. The age distribution chart reflects the periods of significant productivity of three authors: 44 percent of all references in the Milton studies were to pre- 1900 publications; James wrote in the late nineteenth century and the first two decades of the twentieth century, and the references for that period accounted for 33.6 percent of all references; Auden's contributions extended from the thirties, with the sixties being the peak decade with 31.1 percent of all references dating from that period, thus further confirming the importance of the creative work as primary source material in this type of literary research.

\section{LITERARY MOVEMENTS}

Another type of critical concern of literary scholarship centers around the concept of critical theory espoused by literary movements and schools. The intent in this part of the study was to investigate by means of citation analysis (a) the survival rate in current literary scholarship of the doctrines that dominated the literary scene in several countries during a relatively short period of time, (b) to see if there are basic characteristics that separate movements from one another, and (c) whether citation analysis could pinpoint outside influences that shaped and/or dominated literary movements.

Each of the three literary movements selected for the study had its roots in different disciplines, yet the span of time in which they dominated the literary scene was approximately the same-fifteen to twenty years. The proponents of the Symbolist movement of the latter part of the nineteenth century were mostly poets with a cult of beauty, and having close affinities with the fine arts. Existentialism as a literary movement had its roots in philosophic doctrines of the mid-nineteenth and early-twentieth centuries, and its expression flourished with a series of plays and novels during the forties and fifties. The principles of linguistics and cultural anthropology, and their application to literary theory, form the basis of the Struc- turalist movement in literature during the sixties and early seventies. "[Structuralism] sees itself as a 'human science' capable of identifying all the structures that make up a coherent universe. ${ }^{\prime 6}$

The methodology used for this part of the study was the same as the one employed in the information transfer study on creative writers. The AEHCI for 1976, 1978 , and the first months of 1979 yielded a total of 352 source articles: 138 on Symbolism, 78 on Existentialism, and 136 on Structuralism. The subject approach was again derived from the Permuterm Index of articles whose titles included the words symbolism, existentialism, and structuralism. In this instance the articles in the "Source Index" needed more careful scrutiny than in the study on creative writers because these terms in the title could also apply to subject matter not directly dealing with the literary movements under investigation (e.g., the use of symbols in art or religion, the existential philosophers, or theologians of earlier periods).

Of the source articles, 45.5 percent were book reviews, this figure being somewhat lower than the 49.6 percent on creative writers. The preponderance of source articles on Structuralism were books reviews, 60.4 percent as opposed to 35.1 percent on Symbolism and 41 percent on Existentialism. This preponderance may be explained by the "fad" tendency in literary movements. The more contemporary the doctrine, the more controversy or excitement it creates. Consequently, as new books on the subject are being published, proponents or detractors hasten to review them in the various literary bodies. It is also possible that because Structuralism is currently more fashionable than Symbolism, more books are being written on the former than on the latter.

The 352 source articles on literary movements contained 4,144 references. Of these 78.8 percent were to books, 16.5 percent to articles, and 4.6 percent to other types of materials. In comparing these figures to those for creative writers -82.7 percent to books, 15.1 percent to articles, and 2.2 percent to other-there does not seem to be a great deal of difference in distribution by form. The 4.6 percent 
"other" includes references in articles about Symbolism that have a large number of what the AEHCI calls "implicit" citations to paintings.

While the 78.8 percent of referehces to books suggests almost as heavy reliance on books by scholars for their research on critical theory as on creative writers, nevertheless it is a lower percentage and is closer to the 75 percent in Heinzkill in his study on English literary journals ${ }^{7}$ and to the 71.5 percent in Simonton's study on the fine arts. ${ }^{8}$

The source articles dealing with Symbolism had 75.1 percent of their references to books, those on Existentialism 83.3 percent, and Structuralism 78 percent. The time span separating current scholarship from the subject researched doesn't seem to be a factor here. One reason may be that the time span separating the period the literary movement was in vogue and the period the source articles were written is much more condensed-about 100 years-whereas in the study on creative writers it extended through four centuries.

References to journal articles, 15.2 percent on Symbolism, 14.3 percent on Existentialism, and 20.2 percent on Structuralism suggests that while the percentage of references to articles is still much lower than in other humanistic disciplines, the movement derivative from social science disciplines, i.e., Structuralism, shows a markedly higher reliance on journal literature than the other two.

The heavy reliance on primary sources observed in the study on Milton, James, and Auden -47.4 percent of all references were to primary sources-contrasts with the 22.3 percent dealing with the three literary movements. Scholarship in these areas of literary research relies more heavily on works of judgmental and interpretive nature and less so on materials dealing with the creative process itself. In other words, literary researchers use more critical material of other researchers when they write about literary theory than when they write about the creative writer and his work. Of the references in the source articles on Symbolism, 30.5 percent were to primary sources, this figure was 28 per- cent on Existentialism and 8.4 percent on Structuralism, thus, once again, the latter exhibiting characteristics of the social sciences.

The analysis of age distribution of citations presented similar problems to those for creative writers, due to the $A \mathcal{E H C I}$ practice of leaving off publication dates on large numbers of citations. In this study attempts were made to date as many of the undated citations as possible. The remaining undated ones were not included in the count.

Current materials seem to be used heavily by researchers writing on these literary movements. Even allowing for the fact that the movements under study are relatively recent-a time span of 100 yearsalmost 60 percent of the references in all three areas were to materials 20 years old or less, 30.3 percent to 10 years old or less. The age distribution of all references for the creative writers' study showed that 21.6 percent of the references were to materials 10 years or less and 44.7 percent to 20 years or less. Table 5 is a compilation of figures on age distribution of several disciplines as it appeared in the Jones, Chapman, Woods study. ${ }^{9}$ To it are added the distribution figures for the two literature studies.

TABLE 5

\section{AGE DISTRIBUTION OF SEVERAL} DISCIPLINES

\begin{tabular}{lc}
\hline \hline & $\begin{array}{c}\text { \% of published } \\
\text { references ten } \\
\text { years old or less } \\
\text { at the time } \\
\text { of the study }\end{array}$ \\
Subject & 88.2 \\
\hline Physics & 80.0 \\
Sociology & 71.2 \\
Chemistry & 69.9 \\
Sociology & 69.6 \\
Sociology & 57.0 \\
Sociology & 56.2 \\
Business Administration & 50.0 \\
Sociology & 47.6 \\
Politics & 45.0 \\
Economics & 34.9 \\
Philosophy & 30.3 \\
Literary Movements & 25.5 \\
Music & 22.8 \\
Early Modern English History & 21.6 \\
United States History & 21.6 \\
Creative Writers & 17.4 \\
Medieval English History & 13.8 \\
Later Modern English History &
\end{tabular}


The use of primary sources, be it the archival literature used by historians, or the creative works of authors used by literary researchers, seems to be the key factor in determining the extent to which contemporary material (as opposed to current material) is used in scholarly research. A closer analysis of the age distribution of the two literary studies will support this tendency. While the age distribution charts on the creative writers clearly reflect their periods of significant productivity, the chart on the literary movements does not provide similar information on the three movements analyzed. With the exception of Symbolism, where the highest percentage of references dated from the pre- 1900 period ( 30.4 percent), neither for Existentialism nor for Structuralism do the highest percentages of references correspond to the time period when the two movements flourished. This seems to be further indication of those subject areas where contemporary documents are heavily used for research and where they are replaced or substituted by more current, secondary material.

\section{SUMMARY}

Literary research, as reflected in articles written by active scholars in the field of literature, relies heavily on research material published in book form containing primary source material. The more intensively the research deals with the works of creative writers, the heavier the reliance on primary sources, the text of the creative work being the major source. The time span separating the researcher from the creative writer seems to be a contributing factor in the degree to which the textual material is being used. As the body of secondary material and the various critical apparatuses and other editorial structures build up around the works of a creative writer, the use of the text itself decreases in favor of other types of research material directly related to the text. As the focus of research veers from textual studies toward literary theory, while reliance on materials in book form is still decisively prevalent, the role of primary source material becomes markedly diminished. Once the concern turns toward approaches to liter- ary criticism, away from the "purity" of the text, the influences and characteristics of other disciplines also make themselves noticed. Literary theory derived from social science disciplines takes on some of the characteristics of that discipline, i.e., heavier reliance on journal literature and on secondary sources.

The age of the materials used by literary researchers seems to indicate that currency is uniformly an important factor both in research on creative writers and on literary theory. Material ten years old or less about all three creative writers and the two literary movements whose roots are to be found in the humanities fell into the 20-25 percentile range. On the other hand, nearly half ( 44 percent) of the material used on Structuralism was ten years old or less. About half of the material used on creative writers dated from about the time the authors flourished. Similarly, works on literary theory were used heavily from the periods when the literary movements enjoyed high popularity. The age distribution study points to two distinct periods of use in each of the subjects analyzed: the period closest to the time the source articles on the subjects were written, and the period when the subjects of the source articles wrote most of their creative works or when the literary movements were at the height of their popularity.

The validity of these conclusions needs to be further tested by using this same methodology in the analysis of current scholarship on other creative writers and on other areas of literary theory as well as on subfields of other humanistic disciplines. While the $A \mathcal{E H C I}$ promises to become a readily available database for similar bibliometric studies, one has to recognize that the data essential for such analyses are incidental by-products of $A \mathcal{E H C I}$ policy, whose primary aim is to define the content of the indexed articles and to provide access points to documents cited.

The complexity of footnotes is another limiting factor in analyzing citations in the humanities and in using the $A \mathcal{E} H C I$ for that purpose. Bibliographic notes and footnotes often extend to long para- 
graphs, may include several citations to a variety of primary and secondary sources, and may also provide an arena for the airing of controversies over interpretations. Consequently, the task of both indexers and bibliometric analysts becomes more complex and more subject to judgmental determination than the task of those who index or analyze citations in other than literary or humanistic disciplines.
The results of this study support the contention of those humanists and information scientists who maintain that humanistic scholarship and the methods by which their characteristics are categorized and studied are distinctive and unique and don't lend themselves to quantitative analyses the same way as disciplines in the sciences or those close to the sciences do.

\section{REFERENCES}

1. Arts \& Humanities Citation Index. Guide \& Journal List. (Philadelphia: Institute for Scientific Information, 1979), p.23.

2. Ibid, p.20.

3. C. Jones; M. Chapman; and P. C. Woods, "The Characteristics of the Literature Used by Historians," Journal of Librarianship 4:137-56 (July 1972).

4. R. N. Broadus, "The Literature of the Social Sciences: A Survey of Citation Studies," International Social Science Journal 23:236-43 (Apr. 1971).

5. R. Heinzkill, "Characteristics of References in Selected Scholarly English Literary Journals," Library Quarterly 50:352-65 (July 1980).

6. M. Krieger and L. S. Dembo, eds., Directions for Criticism: Structuralism and Its Alternatives (Madison, Wis.: Univ. of Wisconsin Pr., 1977) p.87.

7. Heinzkill "Characteristics of References," p.352-65.

8. Broadus, "The Literature of the Social Sciences," p.236-43.

9. Jones, Chapman, and Woods, "The Characteristics of the Literature," p.137-56. 